\title{
Comparative study of higher volume lower concentration and lower volume higher concentration levobupivacaine in paediatric caudal block for postoperative pain relief in infraumbilical day care surgeries: Randomized observer blinded study
}

\author{
Shilpa Masur ${ }^{1}$, Anilkumar Ganeshnavar ${ }^{2, *}$, Preetika Hiremath ${ }^{3}$, Dinesh Naik ${ }^{4}$ \\ ${ }^{1,4}$ Assistant Professor, ${ }^{2}$ Associate Professor, ${ }^{3}$ PG Student, Dept. of Anaesthesiology, S Nijalingappa Medical College, HSK \\ Hospital and Research Centre, Navanagar, Karnataka, India
}

*Corresponding Author:

Email: anilganesh22@gmail.com

Received: $05^{\text {th }}$ January, 2018

Accepted: $19^{\text {th }}$ April, 2018

\begin{abstract}
One of the commonly used regional anaesthesia technique for postoperative pain relief in paediatric surgery is caudal block. By increasing the volume of local anaesthetics, a higher initial level of blockade might extend the analgesic duration. Our aim was to compare analgesic durations between higher volume lower concentration and lower volume higher concentration levobupivacaine administered to children undergoing infraumbilical day care surgery.

Materials and Methods: After obtaining ethical clearance and informed consent from guardian we performed randomized, prospective, observer-blinded study. Sample size calculated was 24 in each group. Caudal block was performed after induction and securing airway with appropriate size LMA. Children aged 6months to 5yr ASA I-II, received Levobupivacaine either 0.8 $\mathrm{mL} / \mathrm{kg}$ of $0.375 \%$ (lower volume/ higher concentration [Group L], $n 24$ ) or $1.5 \mathrm{~mL} / \mathrm{kg}$ of $0.1 \%$ solution (higher volume/ lower concentration [Group H], $n$ 24) with radioopaque dye. Duration of analgesia and time for the $1^{\text {st }}$ dose of oral acetaminophen was noted.

Results: Fluoroscopic examination showed the spread levels of Levobupivacaine to T12(T12-L2) in Group L and T6 (T4-T8) in Group H. The mean duration of analgesia in Group H was significant than in Group L, i.e., $639.091 \pm 89.8628$ min and $587.028 \pm$ $87.7387(P<0.05)$ respectively: Time for the first dose of oral acetaminophen was found to be significantly longer with Group $\mathrm{H}$ patients than Group L.

Conclusions: Caudal analgesia with higher volume lower concentration of levobupivacaine $(0.1 \%)$ provides longer duration of analgesia than lower volume higher concentration levobupivacaine $(0.375 \%)$ in children undergoing day-care infraumbilical surgery
\end{abstract}

Keywords: Paediatric, caudal, Post operative analgesia, Levobupivacaine, Epidurography.

\section{Introduction}

Caudal anaesthesia is common and effective regional anaesthesia technique for relieving postoperative pain in paediatric surgery ${ }^{1}$.Major limitation of the single-injection technique being its shorter duration of analgesia. ${ }^{1}$ Dose, volume, and concentration of the local anaesthetic solution determines the quality and level of the block. The extent of analgesia following caudal block is dependent on the anatomic spread of solution within the epidural space; which in turn depends on the volume injected. ${ }^{2,3}$ When the total drug dose is fixed, it is uncertain whether the volume or concentration of local anaesthetic influences the spread and quality of caudal analgesia. ${ }^{4,5}$ In children, there is limited data regarding the relative effects of volume and concentration of local anaesthetic solutions used for caudal analgesia and the conclusions are still under debate. ${ }^{1,6,7}$ In addition, no study has assessed the spread of local anaesthetics and its related analgesic duration. So a randomized, prospective, observer blinded study was done where in the volume of the drug was doubled so as to assess the level of spread by fluoroscopic examination and to compare analgesic durations between higher volume/lower concentration (HVLC) and lower volume/higher concentration (LVHC) levobupivacaine when a constant dose was administered to children undergoing day-care surgeries.

\section{Materials and Methods}

The study enrolled 50 paediatric cases between ages 6 months- 5 years weighing less than $15 \mathrm{~kg}$, who underwent infra umbilical surgeries. Institution ethical committee approval was taken and written informed consent obtained from all parents. Patients with history of allergic reactions to any local anaesthetics, bleeding diathesis, infections at the puncture sites, and anatomical abnormalities of lumbosacral region or preexisting neurological disease were excluded from the study. Sample size calculation was done using Open Epi software version 2.3.1. At 95\% confidence level and $80 \%$ power of the study, in a study conducted by Celik, J. B. et $\mathrm{al}^{8}{ }^{8} 20 \%$ of the patients in group 1 required oral acetaminophen as rescue analgesia at $825+-103$ min versus $60 \%$ of patients in group 2 required at 587+-98 $\mathrm{min}$.Sample size calculated was 24 in each group, rounded off to 25. Two anaesthesiologists and a blinded observer were involved 
with each patient. Using computer generated randomization table, patient was randomly assigned to one of the two groups.

All parents were instructed about the use of CHEOPS SCALE ${ }^{8}$ in a preoperative interview. After premedication with glycopyrolate $0.05 \mathrm{mg} / \mathrm{kg}$ and ketamine $1-2 \mathrm{mg} / \mathrm{kg}$ children were shifted to operation theater. Standard monitors were applied, and inhalational induction was done with 8 vol\% of sevoflurane in $100 \%$ oxygen by an anesthesiologist who will be unaware of the patient's group assignment. Airway is secured with appropriate size LMA and anaesthesia maintained with $\mathrm{O}_{2}+\mathrm{N}_{2} \mathrm{O}+$ Sevoflurane $1.5-2 \%$. A second anaesthesiologist who was not involved in the further study administered the caudal block using $5 \mathrm{~cm}$ short bevelled 22-gauge hypodermic needle with the child in lateral position, under aseptic precautions. Children received a fixed dose of freshly prepared levobupivacaine either $0.8 \mathrm{~mL} / \mathrm{kg}$ of $0.375 \%$ (LVHC, $n_{-} 25$ ) or $1.5 \mathrm{~mL} / \mathrm{kg}$ of $0.1 \%$ (HVLC, $n$ _ 25) containing diluted radio opaque dye of 30 $\mathrm{mgI} / \mathrm{mL}$ (Omnipaque ${ }^{\mathrm{TM}}$ 300, GE Healthcare, County Cork, Ireland). Drugs were injected slowly at a rate of 1 $\mathrm{mL} / 3 \mathrm{~s}$ (Fig. 1). The patient was then placed in the supine position for fluoroscopic examination. Fluoroscopic images of the lumbo-sacral or thoracicsacral area were saved, and the spread levels were determined by an anaesthesiologist blinded to the protocol and their determinations were confirmed by an independent radiologist. Surgery was followed 15 minutes after performing the block. Vital parameters like peripheral oxygen saturation, heart rate, and non invasive arterial blood pressure were monitored and recorded throughout the surgery. All measurements were recorded at 5-min intervals. After emerging from anaesthesia, patients were managed by an observer blinded to group allocation in the recovery room (RR). Pain levels in the postoperative ward was assessed using the Children's Hospital of Eastern Ontario Pain Scale (CHEOPS). ${ }^{9}$ Child received rescue analgesic i.v fentanyl $(2 \mu \mathrm{g} / \mathrm{kg})$, if two coupled observations separated by a 5 -min waiting period yielded CHEOPS more than 4. Motor blocks was assessed with a Modified Bromage score (0: no motor block, 1: able to move legs, and 2: unable to move legs ${ }^{10}$ and 8-point modified Ramsay Sedation Scale ${ }^{11}$ was used to evaluate postoperative sedation. Time from when the patient entered the RR to till they could drink water, void, and were fit for discharge was considered as recovery time. Child with clear consciousness, stability of vital signs, ability to tolerate oral fluids and void, age appropriate level of ambulation, and absence of side effects were considered fit for discharge. The interviewer, who was blinded to the treatment group, assessed the need for oral analgesic after discharge and documented these data in the patient's medical record by telephonic conversation with patient parents. The time to first supplemental oral acetaminophen (first acetaminophen time) was defined as the time from the end of surgery to the first registration of a CHEOPS more than 4 by parent's ${ }^{12}$. Student's $t$-test, Mann-Whitney rank sum test, and Fisher's exact test when appropriate, were used to analyze the two groups. Equality of variances was assessed using Levene's test. A linear regression analysis was used to determine whether epidural spread level of levobupivacine is associated with first oral acetaminophen time after discharge. A P value 0.05 was considered significant.

\section{Results}

Study was done on 50 children in which 25 children received LVHC and another 25 received HVLC. Demographic data was similar in both the groups (Table 1). Caudal block was successful in all the patients. Intraoperative haemodynamic parameters were maintained within $20 \%$ of base value in both the groups having no significant variation. No patient received additional analgesics intraoperatively.

Table 1: Patient characteristics

\begin{tabular}{|l|c|c|c|}
\hline & $\begin{array}{c}\text { Group } \\
\text { HVLC } \\
\text { (mean+SD) }\end{array}$ & $\begin{array}{c}\text { Group } \\
\text { LVHC } \\
\text { (mean+- SD) }\end{array}$ & $\begin{array}{c}\text { P } \\
\text { value }\end{array}$ \\
\hline Age (yrs) & $3.44 \pm 1.50$ & $2.59 \pm 1.57$ & 0.064 \\
\hline $\begin{array}{l}\text { Weight } \\
\text { (kg) }\end{array}$ & $12.3 \pm 3.1$ & $11.15 \pm 3.2$ & 0.231 \\
\hline $\begin{array}{l}\text { Duration } \\
\text { of surgery } \\
\text { (min) }\end{array}$ & $50.40 \pm 15.064$ & $48.41 \pm 8.506$ & 0.587 \\
\hline
\end{tabular}

Recovery profiles were similar between both the groups and rescue analgesic of IV Fentanyl was not given to any patient. There were no significant differences in the incidences of vomiting, flushing, deep sedation, or motor block. There was no motor blocked in HVLC. CHEOPS assessed at 30-min intervals in the RR showed similarities between the two groups.

The mean duration of analgesia in Group HVLC was significantly more than in Group LVHC $(P<0.05)$. (Table 2)

\section{Table 2: Mean duration of analgesia}

\begin{tabular}{|c|c|}
\hline Group HVLC & Group LVHC \\
\hline $639.091 \pm 89.8628$ & $587.028 \pm 87.7387$ \\
\hline
\end{tabular}

After discharge, most of the children who received LVHC levobupivacaine, required oral acetaminophen compared with those receiving HVLC .Time for first oral acetaminophen dose was significantly longer with HVLC patients than LVHC patients (Fig. 2). The spread level of higher volume lower concentration levobupivacaine correlated significantly with the first oral acetaminophen time after discharge in both the groups. The spread levels of Levobupivacaine confirmed by epidurography were L1 (T12-L2) in the 
LVHC group and T6 (T4-T8) in the HVLC group (Fig. 3).

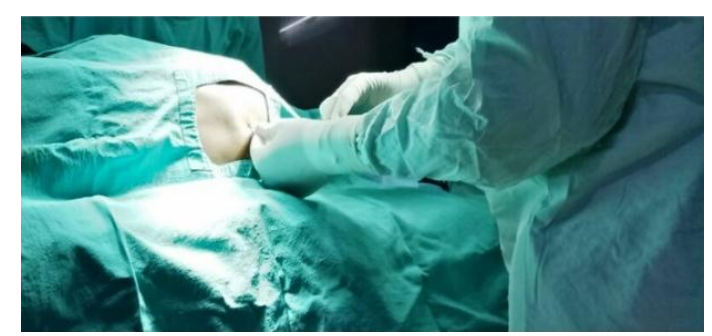

Fig. 1: Administration of caudal anaesthesia

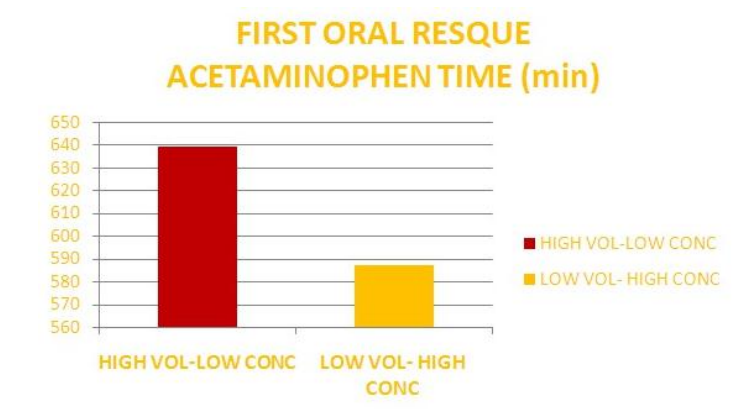

Fig. 2: First oral rescue acetaminophen time in minutes

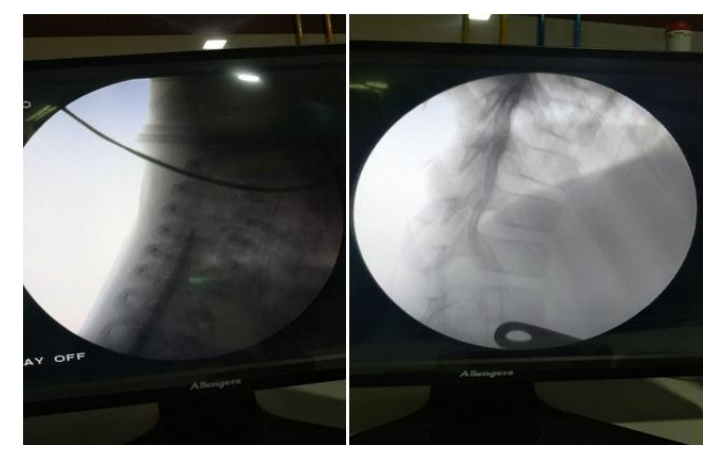

Fig. 3: Level of spread in HVLC and LVHC respectively

\section{Discussion}

From the above results we can demonstrate that when the total dose of levobupivacaine is fixed, a caudal block with HVLC levobupivacaine provides longer analgesic duration than LVHC_levobupivacaine in children undergoing infraumblical day-care surgery. The analgesic duration does depends on the spread level of levobupivacaine in pediatric caudal block. Only limited resources are available regarding the pediatric use of different concentrations of levobupivacaine, for caudal block. Since both racemic bupivacaine and levobupivacaine are equipotent, the presently used concentration of the drug relied on the studies of racemic bupivacaine. We decided to use the concentrations of $0.1 \%$ and $0.375 \%$, which previously have been investigated with regard to the optimum concentration of racemic bupivacaine for caudal blockade in children. ${ }^{13,16}$ Levobupivacaine is an L- isomer of bupivacaine and has advantage of less motor blockage and longer sensorial block and it is less toxic to the central nervous and cardiovascular systems. ${ }^{13,15}$

The two principal dosing variables for local anaesthetics are the concentration and the volume of drug administered. In children, several studies have evaluated the level of the block and duration of post operative analgesia with caudal blocks against concentration and volume of the local anaesthetic. But studies had conflicting results.

Silvani et $\mathrm{al}^{1}$ found that caudal blocks with a HVLC regimen produced prolonged analgesia and fewer side effects compared with a LVHC regimen in children undergoing hypospadiasis repair. Verghese et $\mathrm{al}^{4}$ demonstrated that a caudal block with HVLC is more effective than LVHC in reducing the peritoneal response caused by pulling of the spermatic cord during orchidopexy. They performed a caudal block with a fixed dose of $0.2 \%$ and $0.25 \%$ bupivacaine, but only produced a $20 \%$ difference in volume. Furthermore, they could not differentiate postoperative analgesic duration because of the addition of epinephrine and sodium bicarbonate to their solutions. On the other hand, Schrock and Jones ${ }^{7}$ observed that even increasing the total dose by increasing the volume of a fixed concentration $(0.175 \%)$ of bupivacaine did not prolong the duration of caudal analgesia in children undergoing inguinal herniorraphy. The required volume of caudal analgesic has been evaluated by several authors. Volume per kilogram dosage produces a tight linear correlation with the number of dermatomes anesthetized. ${ }^{16}$ According to the Armitage formula, usually $\quad 0.5-1.25 \quad \mathrm{~mL} / \mathrm{kg}$ of $0.2 \%$ Bupivacaine/ropivacaine is given in caudal analgesia for pediatric surgery. ${ }^{17}$ The goal of our study was to use a larger volume with a smaller concentration to keep the total dose of the drug within a safe limit. Thus $0.1 \%$ ( $1 \mathrm{~mL}$ of $0.5 \%$ levobupivacaine diluted with $4 \mathrm{~mL}$ of saline) and $0.375 \% \quad(7 \mathrm{~mL}$ of $0.5 \%$ levobupivacaine diluted with $3 \mathrm{~mL}$ of saline) levobupivacaine were considered safe and dosage allowed us to keep the drug mass the same while producing a 50\% increase in volume. Using higher volumes resulted in higher levels of spread i.e T6 levels. The level of block was determined by fluoroscopic examination in individual patients of this study, and we confirmed that a $50 \%$ increase in the injectate volume from $0.8 \mathrm{ml}$ to $1.5 \mathrm{~mL} / \mathrm{kg}$ produced five segments higher level of block from T11 to T6 and that the level of caudal block correlated significantly with analgesic duration. Of significance, was the fact that the spread levels of the drug was wide in both the groups. This wide variation in the range is because when higher drug volumes are injected in epidural space the drug not only along spreads along the longitudinal axis but also into the lateral intervertebral foramina. ${ }^{18,19}$ Postinjection (when the X-ray image was obtained), the caudal solution may still be creeping 
cranially and not yet has reached its highest level and there may be 'pharmacological spread' that is not visible to the naked eye on X-ray examination. ${ }^{20}$

Our results also demonstrated that there were no differences in vital parameters like heart rate and blood pressure between the two groups despite the significantly higher spread level of the HVLC compared with the LVHC. The mechanism for this lack of hemodynamic sympathectomy was postulated to be the immaturity of the sympathetic nerve system. In addition, it is also possible that the smaller blood volume that is present in the lower extremities of a young child compared with that of an adult may account for less venous pooling and therefore less hemodynamic change. ${ }^{21}$

No patients in HVLC group had loss of motor activity in lower limbs, making it an ideal volume and concentration of the drug for all the day care sugeries.

Significant end point of the study was, the time for the requirement of first dose of oral acetaminophen which is more in HVLC group is determined by the parent's subjective impression of the child's pain. Since the oral acetaminophen was administered only after discharge, parents were the only assessors of their child's analgesic requirements. Assesment of pain in childrens during post operative period by CHEOPS had varying levels of validity as shown by various studies. ${ }^{22}$

Study could have been carried out on larger group of children so as to determine the exact levels of the caudal block after taking all factors into consideration. We did not measure the plasma levels of levobupivacaine. But none of our patients had signs of the toxicity of LA. Study can be done to assess plasma levels of levobupivacaine as more spread of the drug in epidural space might increase its plasma levels too. Further studies can be done by adding an adjuvant to HVLC levobupivacaine so as to prolong the duration of postoperative analgesia furthermore, thus alleviating the need for caudal catheter placement.

\section{Conclusion}

From the above study, we conclude that the spread level was T12 (T12-L2) with $0.8 \mathrm{~mL} / \mathrm{kg}$ of $0.375 \%$ levobupivacaine and T6 (T4-8) with $1.5 \mathrm{~mL} / \mathrm{kg}$ of $0.1 \%$ levobupivacaine. When the total dose of drug is fixed, a caudal block with higher volume lower concentration levobupivacaine provided extended analgesic duration than lower volume higher concentration levobupivacaine in children undergoing infraumbilical day care surgery. The analgesic duration does depend on the spread level of levobupivacine in pediatric caudal blocking.

\section{Reference}

1. Silvani P, Camporesi A, Agostino MR, et al: Caudal anaesthesia in paediatrics: an update. Minerva Anestesiol,2006;72:453-9.
2. Armitage EN. Local anaesthetic techniques for prevention of postoperative pain. Br J Anaesth 1986;58:790-800.

3. Hong JY, Han SW, Kim WO et al. A comparison of high volume/low concentration and low volume/high concentration ropivacaine in caudal analgesia for pediatric orchiopexy. Anesth Analg 2009;109:1073-8.

4. Dernedde M, Stadler M, Bardiau F, Boogaerts J. Comparison of different concentrations of levobupivacaine for post-operative epidural analgesia. Acta Anaesthesiol Scand 2003;47:884-903.

5. Whiteside R, Jones D, Bignell S, Lang C, Lo SK. Epidural ropivacaine with fentanyl following major gynaecological surgery:the effect of volume and concentration on pain relief and motor impairment. Br J Anaesth 2000;84:720-4.

6. Verghese ST, Hannallah RS, Rice LJ, Belman AB, Patel KM. Caudal anesthesia in children: effect of volume versus concentration of bupivacaine on blocking spermatic cord traction response during orchidopexy. Anesth Analg 2002;95:1219-23.

7. Schrock CR, Jones MB. The dose of caudal epidural analgesia and duration of postoperative analgesia. Paediatr Anaesth 2003;13:403-8.

8. Celik JB, Apiliogullari S, Kara I, Topal A, Yuceaktas A. A Comparison of the effects of caudal anesthesia with constant dosage of levobupivacaine in different volumes and concentrations in children. Erciyes medical journal 2013 vol. 35 no 2 pp. $42-45$ ref .14

9. Crellin D, Sullivan TP, Babl FE, O'Sullivan R, Hutchinson A. Analysis of the validation of existing behavioral pain and distress scales for use in the procedural setting. Paediatr Anaesth 2007;17:720-33.

10. 10.Bromage PR. Mechanism of action of extradural analgesia. Br J Anaesth 1975;47:199-211.

11. Agrawal D, Feldman HA, Krauss B, Waltzman ML. Bispectral index monitoring quantified depth of sedation during emergency department procedural sedation and analgesia in children. Ann Emerg Med 2004;43:247-55.

12. 12.Tarbell SE, Cohen IT, Marsh JL. The ToddlerPreschooler Postoperative Pain Scale: an observational scale for measuring postoperative pain in children aged 1-5. Preliminary report. Pain 1992;50:273-80.

13. Ivani G, De Negri P, Lonnqvist PA, L'Erario M, Mossetti V, Difilippo A, Rosso F. Caudal anesthesia for minor pediatric surgery: a prospective randomized comparison of ropivacaine $0.2 \%$ vs levobupivacaine $0.2 \%$. Paediatr Anaesth 2005;15:491-4.

14. Breschan C, Jost R, Krumpholz R, Schaumberger F, Stettner H, Marhofer P, Likar R. A prospective study comparing the analgesic efficacy of levobupivacaine, ropivacaine and bupivacaine in pediatric patients undergoing caudal blockade. Paediatric Anaesth 2005;15:301-6.

15. Ivani G, DeNegri P, Conio A, Grossetti R, Vitale P, Vercellino C, Gagliardi F, Eksborg S, Lonnqvist PA. Comparison of racemic bupivacaine, ropivacaine, and levo-bupivacaine for pediatric caudal anesthesia: effects on postoperative analgesia and motor block. Reg Anesth Pain Med 2002;27:157-61.

16. Takasaki M, Dohi S, Kawabata Y, Takahashi T. Dosage of lidocaine for caudal anesthesia in infants and children. Anesthesiology 1977;47:527-9.

17. Armitage EN. Local anaesthetic techniques for prevention of postoperative pain. Br J Anaesth 1986;58:790-800 
18. Shantha TR, Evans JA. The relationship of epidural anesthesia to neural membranes and arachnoid villi. Anesthesiology 1972;37:543-57.

19. Moor DC, Bridenbaugh LD, Van Ackeren EG, Belda FB, Cole FV. Spread of radiopaque solutions in the epidural space of the human adult corpse. Anesthesiology $1958 ; 19: 377-85$.

20. 20.Triffterer L, Machata A M, Latzke .D, Willschke H, Rebhandl W, Kimberger O and Marhofer P. Ultrasound assessment of cranial spread during caudal blockade in children: effect of the speed of injection of local anaesthetics. Br J Anaesth 2012;108(4):670-4.

21. Dohi S, Seino H. Spinal anesthesia in premature infants: dosage and effects of sympathectomy. Anesthesiology 1986;65:559-61.

22. Beyer JE, McGrath PJ, Berde CB. Discordance between self report and behavioral pain measures in children aged 3-7 years after surgery. J Pain Symptom Manage 1990;5:350-6. 